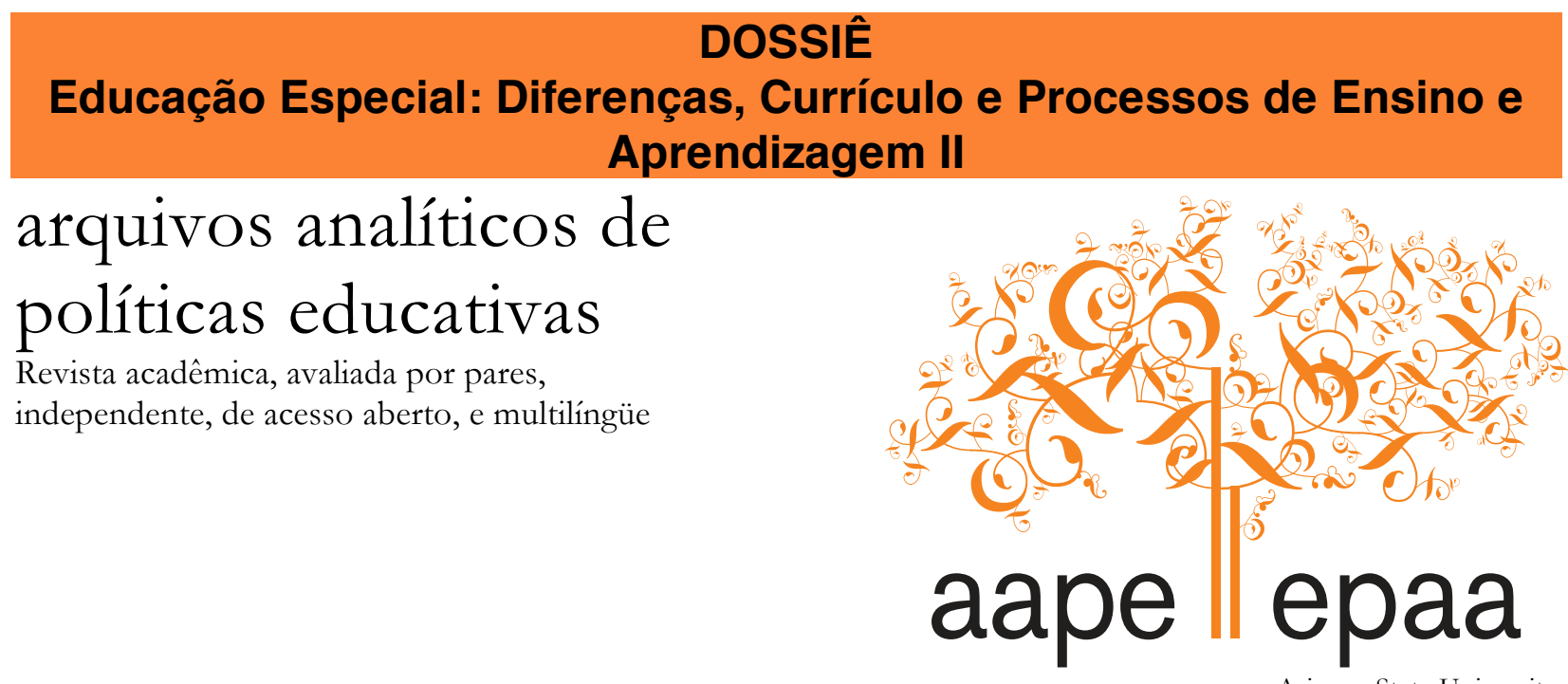

Arizona State University

\title{
Formação Continuada de Gestores Públicos de Educação Especial: Políticas Locais Para a Inclusão Escolar
}

\author{
Denise Meyrelles de Jesus \\ Edson Pantaleão \\ \& \\ Mariangela Lima de Almeida \\ Universidade Federal do Espírito Santo \\ Brasil
}

Citação: Jesus, D. M., Pantaleão, E., \& Almeida, M. L. (2015). Formação continuada de gestores públicos de educação especial: Políticas locais para a inclusão escolar. Arquivos Analíticos de Políticas Educativas, 23(29). Dossiê Educação Especial: Diferenças, Currículo e Processos de Ensino e Aprendizagem II. Editoras convidadas: Márcia Denise Pletsch \& Geovana Mendonça Lunardi Mendes.

http://dx.doi.org/10.14507/epaa.v23.1648

Resumo: Relata o processo de pesquisa-formação, pela via da pesquisa-ação colaborativo-crítica, desenvolvido em 2011 pelo grupo de pesquisa "Educação Especial: formação de profissionais, práticas pedagógicas e políticas de inclusão escolar" resultante da parceria entre a Universidade e a Secretaria de Estado da Educação do Estado do Espírito Santo (ES) junto aos gestores públicos de Educação Especial objetivando articular um processo de formação continuada, na perspectiva da inclusão escolar. Discute, a partir dos resultados de pesquisa recente, questões sobre os processos da educação e escolarização dos alunos público-alvo da Educação Especial, que no Brasil, legalmente, são as pessoas com deficiências, transtornos globais do desenvolvimento e com altas habilidades/superdotação. Conclui que processo de reflexão-ação-crítica instituído pela pesquisaformação relatada propiciou: a) aos profissionais gestores das ações voltadas para as pessoas 
público-alvo da educação especial visibilizar seus saberes-fazeres e a partir de ações coletivas de apoio, instituir, organizar e/ou reorganizar modos de gestão onde ganharam centralidade as políticas locais em ação, em articulação com as políticas educacionais gestadas em escalas regionais e nacionais; b) a ação conjunta da universidade com grupos locais como uma rota sinalizadora de superações de conflitos, tensões e desafios que se colocam a uma ação emancipatória em torno da educação de todos; c) a produção de contribuições para mudanças epistemológicas nas políticas locais e nas formas de ser/estar gestor público de Educação Especial.

Palavras-chave: educação especial; gestores públicos; formação continuada; políticas de educação; inclusão

\section{Continuing Education for Public Administrators in Special Education: Local Policy for School Inclusion}

Abstract: It reports the research-training process through collaborative critical action research, carried out in 2011 by the team of research Special Education: professional training, pedagogical practice and school inclusion policy, which results from a partnership between the Federal University of Espírito Santo and Espírito Santo Secretariat of Education, Brazil along with public special education administrators. This venture aimed at integrating the continuing education process from the school inclusion perspective. Based on recent research results, it discusses question about the education of special education target students, who, according to Brazilian laws, are individuals with disabilities, pervasive developmental disorders or high-potential/gifted learners. It concludes that the reflectionaction-critic process instituted by the study research-training allowed a) administrators of actions aiming special education to visualize their knowledge-action and, based on group actions, institute, organize and/or reorganize managing methods that became central to local policies integrated with state and national policies; b) team work between the university and local groups as a means to overcome conflicts, stress and challenges posed to emancipation of education of individuals; c) production of contributions to epistemological changes in local policies and in the modus operandi of the public special education administrator.

Keywords: special education; administrators; continuing education; education policy; inclusion

\section{Formación Continuada de Gerentes Públicos de Educación Especial: Políticas Locales para la Inclusión Escolar}

Resumen: Relata el proceso de investigación-formación, mediante la investigación-acción colaborativo-crítica, desarrollada en 2011 por el grupo de estudio Educación Especial: formación de profesionales, prácticas pedagógicas y políticas de inclusión escolar resultado de la sociedad entre la Universidad y la Secretaría de Estado de Educación del Estado de Espírito Santo (ES) junto a los gerentes públicos de Educación Especial con el objetivo de articular un proceso de formación continuada, en la perspectiva de la inclusión escolar. Discute, a partir de los resultados de las recientes investigaciones, cuestiones sobre los procesos de la educación y escolarización de los alumnos público objeto de estudio de la Educación Especial, que en Brasil, legalmente, son las personas con deficiencias, trastornos globales del desarrollo y con altas habilidades/superdotados. Concluye que proceso de reflexión-acción-crítica instituido por la investigación-formación relatada proporcionó: a) a los profesionales gerentes de las acciones direccionadas hacia las personas público objeto de estudio de la educación especial visibilizar su "conocer-hacer" y a partir de acciones colectivas de apoyo, instituir, organizar y/o reorganizar modos de gerencia donde ganaron centralidad las políticas locales en acción, en articulación con las políticas educacionales gestadas a escalas regionales y nacionales; b) la acción conjunta de la universidad con grupos locales como una ruta de señalización de superaciones de conflictos, tensiones y desafíos que se colocan a una acción emancipadora de la 
educación de todos; c) la producción de contribuciones para cambios epistemológicos en las políticas locales y en las formas de ser/estar gerente público de Educación Especial.

Palabras-clave: educación especial; gerentes públicos; formación continuada; políticas de educación; inclusión.

\section{Introdução}

Produções recentes evidenciam grandes movimentos sociais, políticos e educacionais em torno de uma proposta mais inclusiva de educação, assumindo o princípio da educação de todos. Em âmbito nacional e internacional, temos encontrado apontamentos sobre a necessidade de os poderes locais se organizarem no sentido de trabalhar de forma articulada e conjunta, fomentando novas relações no interior dos sistemas públicos.

Parrilla (2011, p. 19) diz de um desenvolvimento local articulado ao global, mas na perspectiva de referência do

[...] contexto local como centro e âmbito de gestão do global, [entendendo-se a

possibilidade de] equacionar o problema global da exclusão [que] pode e deve ser

resolvido a partir das perspectivas e ações localmente situadas, fundamentadas e geradas.

A autora sinaliza para a relevância do envolvimento das escolas no debate político. Contudo, evoca a importância da articulação com a comunidade educativa, com os serviços e órgãos regionais compromissados em gestar e gerir as políticas públicas e acompanhá-las em ação, compartilhando uma ética do direito subjetivo à educação e uma aposta na educabilidade de todos, corroborando os argumentos de Meirieu (2005).

Articulados a esse debate, a partir dos resultados de pesquisa recente, discutiremos, neste texto, questões que se reportam, especificamente, aos processos da educação e escolarização dos alunos público-alvo da Educação Especial que, no Brasil, legalmente, são as pessoas com deficiências, transtornos globais do desenvolvimento e com altas habilidades/superdotação (Brasil, 2008).

Muitas tensões envolvem essa categorização, bem como os processos desencadeados para se chegar a tais definições. Há concordâncias, mas também inúmeros conflitos sobre a temática, e a literatura nacional revela diferentes posições (Caiado et al., 2011; Garcia, 2011; Jesus \& Alves, 2011; Tezzari \& Baptista, 2011).

Concordamos que muitos fatores entram no jogo de construir processos mais inclusivos de educação. Dentre eles, queremos destacar a essencialidade dos processos de formação de profissionais da área da educação, para que a escola comum se configure como locus de inclusão, onde devem estar todos os alunos, independentemente de quaisquer condições cognitivas, físicas, sociais, econômicas, étnicas, de gênero e de idade.

Diante da necessidade de garantir escolaridade a alunos que, até o início dos anos 90, frequentavam instituições especializadas, que na maioria dos casos ofertava atendimentos em uma perspectiva clínica, a LDB 9394/96 estabeleceu a matrícula, preferencialmente na rede regular de ensino, conforme já preconizado pela Constituição Brasileira (1988).

Muitos outros aparatos legais ao longo dos anos 2000 foram regulamentando, a matrícula, medidas facilitadoras da permanência, tais como a remoção de barreiras arquitetônicas e criando condições para possibilitar a função da escola, ou seja, a aprendizagem com qualidade social. Dentre os movimentos destacam-se aqueles que se direcionaram à formação do professor, como medida necessária à implantação de uma política educacional mais inclusiva. 
A Resolução CNE/CP n¹/2002, que instituiu as Diretrizes Curriculares Nacionais para a Formação de Professores da Educação Básica, estabeleceu que as instituições de ensino superior deveriam, em sua organização curricular para a formação docente, garantir conhecimentos considerando a diversidade e, em especial, que incorporasse conhecimentos sobre as especificidades dos alunos com necessidades educacionais especiais (nomenclatura à época).

Entretanto, destaca-se que nesse terreno de instituição política, as diretrizes de 2002 apresentaram princípios de instrumentalização técnica na formação, o que reforça a ideia do professor competente, resgatando a perspectiva tecnicista, de cunho tayloriano, conforme destaca Lima (2008). Os saberes docentes se fundamentariam, pela proposta das diretrizes, em manejar instrumentos e técnicas que garantiriam o seu fazer docente.

Essa perspectiva de formação também aparece nas Diretrizes Curriculares Nacionais para o Curso de Pedagogia, regulamentadas pela Resolução CNE/CP n ${ }^{\circ} 01$ de 2006. As propostas de formação presentes nessas diretrizes evidenciam o aligeiramento da formação de professores e, paradoxalmente, propõem uma formação ampliada. Essas diretrizes propõem, por exemplo, uma formação de professores para atuação na Educação Infantil e nos Anos Iniciais do Ensino Fundamental, destacando a possibilidade de atuação desse profissional em espaços escolares e nãoescolares, bem como em processos de gestão da escola e dos sistemas de ensino.

Associada a essa formação e para garantir a aprendizagem de todos os alunos, vale lembrar que o profissional também precisa construir conhecimentos específicos para assegurar a inclusão escolar dos alunos com deficiência, transtornos globais de desenvolvimento e altas habilidades/superdotação, conforme indicativos das diretrizes e do documento orientador das "Políticas Nacionais de Educação Especial na perspectiva da Educação Inclusiva".

No percurso histórico da política educacional brasileira, em 2007, o Plano de Desenvolvimento da Educação - PDE, reafirma o projeto de inclusão escolar das pessoas com deficiência, tendo como eixos a acessibilidade arquitetônica dos prédios escolares, a implantação de salas de recursos e a formação docente para o atendimento educacional especializado (Brasil , 2008).

A meta de formação de professores para o atendimento educacional especializado, e demais profissionais da educação na perspectiva da inclusão se fortalece, destacando-se tanto o professor especializado quanto o professor de sala de aula comum. As prescrições apontam que, para atuar na educação especial,

[...] professor deve ter como base da sua formação, inicial e continuada, conhecimentos gerais para o exercício da docência e conhecimentos específicos da área. Essa formação possibilita a sua atuação no atendimento educacional especializado e deve aprofundar o caráter interativo e interdisciplinar da atuação nas salas comuns do ensino regular, nas salas de recursos, nos centros de atendimento educacional especializado, nos núcleos de acessibilidade das instituições de educação superior, nas classes hospitalares e nos ambientes domiciliares, para a oferta dos serviços e recursos de educação especial (Brasil 2008).

A Política Nacional de 2008 sinaliza que, [...] Esta formação deve contemplar conhecimentos de gestão de sistema educacional inclusivo, tendo em vista o desenvolvimento de projetos em parceria com outras áreas, visando à acessibilidade arquitetônica, os atendimentos de saúde, a promoção de ações de assistência social, trabalho e justiça (pp.18-19).

Observa-se que, atualmente, ainda se coloca como um dos desafios à área de Educação Especial a formação de professores de classe comum e especializados, bem como a formação de outros profissionais em cargos de gestão escolar, gestão de sistema e coordenação pedagógica e curricular. Vários estudos têm se colocado o desafio de analisar essa questão (Figueiredo, 2010; Magalhães \& Cardoso, 2011; Tezzari \& Baptista, 2011; Voltrone \& Mendes, 2012). Outros estudos têm assumido 
a responsabilidade de colocar em análise tais questões nos espaços locais (Givigi, Alves, Alcântara, \& Santos, 2012; Pantaleão, 2009; Vieira, Cuevas, \& Ramos, 2012).

A resolução n ${ }^{\circ} .4$, de 2 de outubro de 2009 , também é clara ao definir as funções dos professores especializados e estabelecer que os sistemas de ensino deverão garantir o funcionamento da educação especial em uma perspectiva inclusiva. No entanto, nenhum ordenamento se coloca diretamente a responsabilidade de sistematizar com/nos sistemas esse processos, tendo em vistas a ação de gestores públicos que se responsabilizem por ações que ultrapassam a tarefa docente de sala de aula.

O Decreto 7611/11 que dispõe sobre a educação especial, o atendimento educacional especializado e dá outras providências evidencia como função prioritária da União garantir apoio técnico e financeiro aos sistemas públicos, dentre outros, tendo em vista garantir a escolarização de alunos público alvo da Educação Especial. No art. $5^{\circ}$ estabelece

$\int 2^{\circ}$ O apoio técnico e financeiro de que trata o caput contemplará as seguintes ações:

I - aprimoramento do atendimento educacional especializado já ofertado;

II - implantação de salas de recursos multifuncionais;

III - formação continuada de professores, inclusive para o desenvolvimento da educação bilíngue para estudantes surdos ou com deficiência auditiva e do ensino do Braile para estudantes cegos ou com baixa visão;

IV - formação de gestores, educadores e demais profissionais da escola para a educação na perspectiva da educação inclusiva, particularmente na aprendizagem, na participação e na criação de vínculos interpessoais;

$\mathrm{V}$ - adequação arquitetônica de prédios escolares para acessibilidade; $[\ldots]$.

VI - elaboração, produção e distribuição de recursos educacionais para a acessibilidade

Para além, as questões de financiamento da Educação/Educação Especial, do transporte, das atividades intersetoriais, do censo específico da população alvo são ações subjacentes ao cargo de gestores. Sob o impacto de tais responsabilidades, pergunta-se: quem está formando os gestores responsáveis nos sistemas públicos pela realização de tais ações?

Em âmbito político, legislações nacionais têm desencadeado movimentos para que os espaços locais sejam locus de organização e articulação para a implementação de políticas públicas para a garantia do direito à educação de todos. Especificamente em relação à Educação Especial, a Resolução n ${ }^{\circ}$ 02/2001, que instituiu as diretrizes da Educação Especial na Educação Básica, convocou os sistemas de ensino a fazer funcionar um setor de Educação Especial para que, colaborativamente com as unidades de ensino, instituíssem ações visando à garantia do conhecimento a esses estudantes: "Os sistemas de ensino devem contribuir e fazer funcionar um setor responsável pela educação especial, dotado de recursos humanos, materiais e financeiros que viabilizem e deem sustentação ao processo de construção da educação inclusiva" (Conselho Nacional de Educação, 2001, art. $3^{\circ}$ ).

A materialização dessas ações legais se deu por meio da instituição de políticas públicas visando à formação continuada dos educadores, à articulação da Educação Especial com o ensino comum, à reestruturação arquitetônica das escolas e à ressignificação do currículo, das práticas pedagógicas e da avaliação (Brasil, 2008).

Paralelamente aos movimentos construídos em âmbito nacional, no delineamento de diretrizes para a implementação de políticas públicas de Educação Especial na perspectiva da inclusão escolar, encontramos iniciativas também nas esferas estaduais e municipais. Muitos Estados brasileiros vêm fazendo cumprir o que determina a legislação nacional, trazendo, para o organograma das Secretarias de Educação, um setor que, em diálogo com os demais departamentos 
desse órgão central - Ensino Fundamental, Educação Infantil, Ensino Médio, Educação Profissionalizante e Educação de Jovens e Adultos - dará subsídios às unidades de ensino para garantir a Educação Especial em uma perspectiva inclusiva.

No contexto capixaba, o Governo do Estado do Espírito Santo, pela via da Secretaria de Estado da Educação, em colaboração com profissionais da área e com a Universidade Federal do Espírito Santo, instituiu as Diretrizes da educação especial na educação básica e profissional para a rede estadual de ensino, cujo objetivo é:

[...] a implementação de uma política de educação especial para subsidiar o Sistema Estadual de Ensino do Estado do Espírito Santo buscando a organização de escolas que atendam a todos os alunos sem nenhum tipo de discriminação/exclusão; escolas estas que valorizem as diferenças como fator de enriquecimento do processo educacional, transpondo barreiras para a aprendizagem e a participação com igualdade de oportunidades (Espírito Santo, 2011, p. 6).

Esse contexto faz emergir uma pluralidade de ações para que os alunos, sujeitos da Educação Especial, estejam matriculados nas escolas de ensino comum. Entretanto, resultados de pesquisas realizadas no Espírito Santo (Gonçalves, 2008; Jesus, 2008, 2009, 2011; Pantaleão, 2009) apontam fragilidades presentes nos sistemas educacionais e apresentadas pelos profissionais que respondem pela gestão da Educação Especial nos municípios capixabas. Encontramos um panorama em que a grande maioria dos municípios não possui setor de Educação Especial ou responsável pelas ações dessa modalidade de ensino. Essa realidade evidencia dificuldades na implementação de políticas que garantam processos de escolarização às pessoas público-alvo da Educação Especial.

Na linha de pensar uma escola pública de qualidade para todos, temos observado, nacionalmente, um movimento em torno da formação de gestores. Especificamente na área de Educação Especial percebemos uma articulação de formações de escopo nacional, como o Programa Educação Inclusiva: Direito à Diversidade (Brasil, 2005). O Ministério da Educação e Cultura (MEC) em parceria com os sistemas estaduais e municipais, incorporou, pela via do Programa, a lógica de municípios-pólos exercendo o papel de multiplicadores. O objetivo do Programa

[...] é a formação de gestores e educadores para efetivar a transformação dos sistemas educacionais em sistemas educacionais inclusivos, tendo como princípio, a garantia do direito dos alunos com necessidades educacionais especiais de acesso e permanência, com qualidade, nas escolas regulares (Brasil, 2005, p. 9).

Cabe destacar que os estudos que o avaliaram em sua organização/realização locais evidenciaram que tal programa não cumpriu a tarefa de formar gestores públicos, visto que muitas das vezes, teve foco na formação do professor especializado e não nas ações específicas da gestão pública de tais processos (Caiado \& Laplane, 2009; Jesus, 2012).

Entendemos que se constituir gestor pressupõe a apropriação de conhecimentos gerais e específicos na área da educação, que demandam uma formação para lidar com o espaço coletivo de forma democrática e ética, pois a Educação Especial, como modalidade de educação e área de conhecimento específico, precisa ser articulada às políticas de educação em geral, a fim de garantir o processo de inclusão social do sujeito público-alvo da educação especial, pela via da escolarização.

Nesse sentido, a equipe de gestão da educação precisa articular o conhecimento específico da Educação Especial com a educação geral, para desencadear políticas que atendam à perspectiva de inclusão escolar.

Considerando o corpus de conhecimento constituído a partir das diferentes pesquisas, nossos estudos evidenciaram a necessidade de investimentos na formação de gestores públicos de Educação Especial, mediante as diretrizes nacionais e estaduais para a modalidade, na perspectiva da inclusão escolar.

Nosso desafio foi articular uma formação com o Poder Público estadual de maneira a 
responder às políticas, tendo em vista as diretrizes da educação inclusiva e as necessidades dos profissionais envolvidos no estudo. Assim, assumimos como princípio a construção coletiva do conhecimento e os participantes como protagonistas nesse processo. Simultaneamente, buscamos nos afastar dos projetos prontos a partir dos órgãos centrais que, na maioria das vezes, não consideram as tensões e desafios dos que estão nos espaços locais e que têm sido avaliados por seus participantes de forma negativa (Laplane \& Caiado, 2008), por não reconhecerem suas principais demandas.

Esse contexto nos levou, como grupo de pesquisa, ${ }^{1}$ a articular uma formação continuada de gestores públicos de Educação Especial, na perspectiva da inclusão escolar. Assim, este artigo tem por objetivo discutir o processo da pesquisa-formação que nos colocamos como desafio ao construir um processo formativo pela via da pesquisa-ação colaborativo-crítica, em parceria com a Universidade e a Secretaria de Estado da Educação/ES.

\section{O Estudo: Construção Coletiva do Processo de Formação}

A pesquisa buscou, por meio de uma proposta de formação continuada para profissionais gestores públicos da Educação Especial, propiciar o desenvolvimento de ação coletiva de metaanálise crítica com profissionais responsáveis pela gestão pública da modalidade de Educação Especial no Estado do Espírito Santo. Para isso, tomamos, teórico-metodologicamente, o referencial da pesquisa-ação colaborativo-crítica. Suas bases epistemológicas e metodológicas são alicerçadas na crítica emancipatória e na colaboração entre pesquisadores e participantes (Carr \& Kemmis, 1988).

Nossa aposta foi no diálogo e na colaboração entre Universidade e Redes Públicas de Ensino, pesquisadores da academia e profissionais-pesquisadores do sistema. Como propósito, buscamos constituir processos de pesquisa que procurem superar os limites do racionalismo positivista e o relativismo desmedido do pragmatismo; assim, é possível pensar em alunos e professores como sujeitos de conhecimento (Almeida, 2010). Neste caso, pensando todos os envolvidos como sujeitos que aprendem.

Com a pesquisa-ação, procuramos promover a aproximação entre sujeito e objeto, assumindo a colaboração como essencial ao processo de mediação, tendo em vista descobrir novos e outros sentidos da realidade. A ênfase se colocou no processo de autorreflexão coletiva em que pesquisadores acadêmicos e pesquisadores da escola buscam mudanças possíveis para as práticas educativas e sociais.

Todo o processo de pesquisa deu-se por meio do diálogo e da escuta, pois conforme Barbier (2002, p. 94) cabe ao pesquisador desenvolver uma escuta sensivel, pela qual " [...] deve saber sentir o universo afetivo, imaginário e cognitivo do outro para 'compreender do interior' as atitudes e comportamentos, o sistema de ideias, de valores, de símbolos e de mitos".

\section{O Curso de Gestores Públicos em Educação Especial: A Pesquisa-Ação Formação}

Fundamentados nos princípios da pesquisa-ação colaborativo-crítica, assumimos uma perspectiva intersubjetiva nas relações estabelecidas entre pesquisadores e sujeitos gestores, pela via do entendimento mútuo, tendo a colaboração e a negociação como eixos condutores dos processos

\footnotetext{
${ }^{1}$ Grupo de Pesquisa "Educação Especial: formação de profissionais, práticas pedagógicas e políticas de inclusão escolar", diretório do Conselho Nacional de Desenvolvimento Científico e Tecnológico (CNPq, Brasil).
} 
investigativos. Nesse sentido, todo o processo de pesquisa-formação deu-se por meio do diálogo e da escuta, pois conforme Barbier (2002, p. 94), cabe ao pesquisador desenvolver uma escuta sensivel, pela qual "[...] deve saber sentir o universo afetivo, imaginário e cognitivo do outro para 'compreender do interior' as atitudes e comportamentos, o sistema de ideias, de valores, de símbolos e de mitos."

Inicialmente, realizamos cinco encontros regionais com os gestores de Educação Especial utilizando a estratégia dos grupos focais (Gatti, 2005), os quais propiciaram um processo de engajamento dos profissionais. Como nos sugere Lapassade (2005), no lugar de escolher o que seria preciso observar e descrever, procuramos conhecer o que os sujeitos conheciam e o que faziam, ver o que viam, e compreender o que compreendiam sobre: tensões e desafios encontrados na atuação; formas de enfrentamento dos desafios da gestão; informações, conhecimentos e conteúdos necessários para a formação e atuação; indicações para a configuração de um currículo de formação continuada.

Assim, numa perspectiva da reflexão-ação-reflexão, a dinâmica do próprio grupo possibilitou o desencadeamento de ideias coletivas, propiciando uma rede de interações mais aprofundadas em eixos temáticos que sustentaram a construção do currículo do curso de formação continuada dos gestores públicos da Educação Especial. Assumimos, portanto, um pressuposto teóricoepistemológico fundamental da pesquisa-ação nesta perspectiva: a negociação do problema e da demanda investigada. Segundo Almeida (2010), embora os pesquisadores da academia tenham previamente uma temática de pesquisa, até mesmo um problema inicial, é a partir da vivência no campo que o problema vai sendo negociado.

Nesse contexto, o segundo momento da pesquisa constituiu-se em um processo de formação continuada a partir de um curso de aperfeiçoamento semipresencial, intitulado Curso de Gestores Públicos em Educação Especial na Perspectiva da Inclusão Escolar. O curso teve como objetivo central formar profissionais gestores que pudessem se constituir em impulsionadores das questões da gestão da Educação Especial, considerando-os como mediadores em sua região de abrangência, tendo como premissa teórico-metodológica a formação-ação.

Participaram gestores e técnicos da rede pública (municipal e estadual) da Educação Especial do Estado do Espírito Santo pertencentes a: onze Superintendências Regionais de Educação (SRE) do Estado do Espírito Santo; setenta e uma secretarias municipais de educação (ES) e três técnicos da Secretaria da Educação (SEDU) central (ES). Vale destacar que dos cento e treze profissionais que iniciaram o curso, cento e quatro finalizaram, ou seja, tivemos um aproveitamento de 92,03\% no que se refere à participação.

No geral, o curso teve a duração de 200 horas sendo, 102 horas presenciais e 98 horas de atividades não presenciais, no período de maio a novembro de 2011.

\section{Vivenciando a Formação em seus Momentos Presenciais}

A organização dos encontros presenciais ocorreu a partir de exposições dialogadas, discussões, palestras e reflexões em grupos. Os eixos temáticos foram constituídos desde o primeiro momento da pesquisa, quando analisamos as demandas dos gestores.

O desafio foi pensar, simultaneamente, uma pesquisa e um curso de formação continuada constituído com os participantes.

A proposta curricular do curso foi construída após uma rigorosa análise das proposições grupais. O grupo de pesquisadores-formadores debruçou-se sobre os indicadores e, em um trabalho de ir-e-vir, sistematizou uma proposta de currículo articulada à realidade e demandas apontadas pelos profissionais gestores, sem, no entanto, deixar de dialogar com os referenciais teóricos sobre a temática.

Constituímos um currículo com a configuração estrutural de sete blocos temáticos, a saber: 
- contextualização histórica da deficiência e da Educação Especial;

- políticas de educação e da educação especial no Brasil em análise;

- gestão de sistemas de ensino;

- gestão escolar e interfaces com a gestão de sistema;

- os sujeitos da Educação Especial e gestão escolar;

- intervenção pedagógica com os sujeitos da Educação Especial;

- realização e socialização de planos de trabalho para intervenção nas realidades locais. A partir do nosso entendimento, esperava-se dos gestores ações de mediação de forma a incentivar, facilitar e acompanhar a construção de políticas públicas que favoreçam a formação de cidadãos que participem na transformação da sociedade.

Assumimos, como princípio articulador do currículo, que a seleção de temáticas não se sustentam sozinhas. São as relações entre os envolvidos que funcionam como mediadoras nos processos de conhecimento (Jesus, 2008; Passerino, 2011). A necessidade de colocar o currículo em ação aproximou o grupo de formação e os gestores de Educação Especial. O próprio movimento da dinâmica formativa foi incorporando novos elementos ao processo. Elementos esses que não estavam prescritos, mas que se aproximavam dos conteúdos estudados porque iam se constituindo na própria dinâmica da formação.

Vieira et al. (2012), ao analisar os movimentos disparados pelo processo de formação em seus momentos presenciais, aponta que quatro pilares emergiram dos processos de formação:

- necessidade de assumir que uma formação com qualidade requer disponibilidade, organização e comprometimento do sujeito em formação com seu processo formativo;

- aprofundamento teórico-prático como um dos elementos fundantes que sustenta os processos de formação;

- relevância da composição do currículo considerando as demandas e as experiências dos participantes em diálogo com a literatura;

- cursistas constituindo-se gestores em movimentos de ação-reflexão.

A intenção de mudança implementava um processo de compreensão da realidade, por meio da reflexão partilhada. Para Pantaleão (2009), ao provocar a formação do outro, o sujeito está implicado na sua própria formação.

Pode-se afirmar que produzimos conhecimento em um processo de reflexão-ação-crítica. $\mathrm{O}$ processo de reflexão se deu no coletivo e individualmente, ganhando diferentes contornos ao longo do tempo e para diferentes profissionais gestores públicos de Educação Especial.

Concordamos com Silva (2005), quando afirma que o currículo tem como base de sustentação o trabalho com o conhecimento. Esse conhecimento tem a função de ampliar as possibilidades de compreensão das pessoas, possibilitando que problematizem as relações estabelecidas no contexto social, acompanhem as produções e invenções humanas e contribuam com este processo evolutivo de criação de saberes e experiências.

Assim como Gatti (2008), acreditamos que o propósito da formação continuada é o de aprimoramento de profissionais nos avanços, renovações e inovações de suas áreas, dando sustentação à sua criatividade pessoal e a de grupos profissionais, em função dos rearranjos nas produções científicas, técnicas e culturais.

Santos (2006) afirma que vivemos um momento com grandes possibilidades de produção de conhecimento. O desafio é pensar a vida em sociedade a partir de um conhecimento que aponte novas possibilidades de transformação da desigual sociedade em que vivemos e que seja assumido que as pessoas precisam ser reconhecidas como sujeitos de conhecimento e de direito. 


\section{Vivenciando a Formação Continuada em seus Momentos Semipresenciais}

Para o momento não presencial, prioritariamente, tínhamos dois objetivos pensados: o primeiro foi o acompanhamento dos cursistas em suas leituras dos textos propostos pelos professores nos momentos presenciais; e o segundo constituiu-se na elaboração de um plano de ação/projeto de intervenção, tendo em vista sua consolidação no ano de 2012.

Tais metas nos desafiaram todo o tempo, visto que, conforme analisado por Araujo e Schwartz (2009, p. 17), pensávamos o curso “[...] pautados pela dimensão do desafio de oferecer um curso com qualidade [...]", mas, como as autoras, entendíamos a complexidade de trabalhar com uma proposta que, em nosso caso, tinha em parte características de um curso a distância, embora semipresencial. As ferramentas da Educação a Distância (EAD) não foram assumidas pelo grupo como o formato a ser trabalhado. Víamo-nos diante de um dilema, assim retratado por uma mestranda do grupo de pesquisa: "Sempre tive um pouco de resistência a essa modalidade". Outra integrante perguntava: "Será que sabemos trabalhar com EAD, ou melhor, queremos?".

Tínhamos clareza de que estávamos compromissados com a construção do conhecimento e, conforme Araujo e Schwartz (2009, p. 17), queríamos “[...] superar a lógica simplista da certificação sem qualidade". Foi, então, no contexto do vivido que o grupo de formadores e o grupo de cursistas-gestores aprendeu a lidar com o desafio das atividades a distância, considerando a "espacidade" como elemento que poderia ser não dificultador do processo de formação continuada de gestores públicos de Educação Especial e do fazer dos formadores, reconhecendo-a como elemento intrínseco com o qual se pode lidar a partir de um processo mediador comunicativo entre os envolvidos.

Foi, então, no contexto do vivido que o grupo de formadores e o grupo de cursistas gestores foram lidando com o desafio das atividades a distância, considerando a espacidade a partir de um processo mediador comunicativo entre os envolvidos, conforme sugerido por Santos (2009), quando discute o Programa Nacional Escola de Gestores: O sistema comunicativo deve, dessa forma, possibilitar o diálogo entre os protagonistas, a participação, o compartilhamento, as trocas, enfim, os elementos necessários à realização da aprendizagem dos atores envolvidos (Santos, 2009, p. 25).

Assumindo esses princípios, propusemos aos profissionais gestores a construção de Planos de Trabalhos acompanhados de um projeto de intervenção para o Setor de Educação Especial da Secretaria Municipal de Educação ou Superintendência Regional de Ensino (SRE), a serem implementados no ano seguinte ao curso (2012). A construção do Plano de Trabalho teve como objetivo central a (re)estruturação do Setor de Educação Especial para 2012.

Nossa intenção foi que os municípios e as superintendências pudessem construir redes de colaboração nessa construção, uma vez que um projeto dessa natureza tem como propósito a transformação de uma determinada realidade, entendida aqui como uma demanda, uma necessidade identificada no processo de diagnóstico da realidade em questão.

A partir da construção de um plano de trabalho para o setor de Educação Especial e de seus espaços locais (municípios e superintendências regionais), buscamos constituir redes de colaboração em processo. $\mathrm{Na}$ organização de cinco grupos, aproximamos SRE's de uma mesma região (norte, central e sul) do Estado, os municípios que lhes são jurisdicionados, bem como os próprios municípios entre si, tendo em vista a elaboração dos planos de trabalho.

Os grupos se reuniram em encontros centralizados na Universidade Federal do Espírito Santo (UFES) e em encontros descentralizados em diferentes municípios. Foram três encontros realizados na UFES e um realizado em superintendências ou Secretarias Municipais de acordo com cada grupo.

Apostávamos nos "[...] processos grupais, em desenvolvimento coletivo, embora nada estivesse estabelecido de antemão” (Jesus, 2009, p. 154). Nesses termos, além de aspectos 
pedagógicos e administrativos, o projeto assume um caráter político, pela via da constituição de grupos de reflexão-colaboração. Uma colaboração que pudesse ser mola propulsora de parcerias nas proposições e ações previstas para o Setor de Educação Especial. Meirieu (2005, p. 153) nos auxilia nessa perspectiva quando aponta para a necessidade de "[...] dialogar, propor, construir, instituir possibilidades/experiências que possam motivar o outro".

Aos poucos, fomos nos constituindo como grupo por meio da autorreflexão organizada (Carr \& Kemmis, 1988), em que os participantes-gestores se tornavam também, autores da pesquisa, investigadores de seus cotidianos para a construção dos planos de projetos.

Os grupos foram orientados considerando as especificidades locais, possibilidades e propostas de cada um deles e as diferenças e tendências internas. Nosso olhar capturou que o envolvimento pessoal, mas também a capacidade de "contagiar do grupo de cursistas" foram muito importantes para a produção coletiva.

Entendíamos a dinâmica do coletivo e os fluxos das interações como elementos que potencializam as ações e interações em pesquisa-ação (Barbier, 2002). As discussões exigiam um diálogo contínuo com a teoria, de forma a permitir a avaliação dos contextos e a reflexão crítica coletiva tendo em vista as proposições de ação coletivo-grupal. A teorização levava ao processo de constituição de conhecimento sobre as realidades locais em suas demandas:

O processo, nessa perspectiva, é uma rede simbólica e dinâmica, construído pelo pesquisador coletivo a partir dos elementos interativos da realidade, aberto à mudança e, necessariamente, inscrito no tempo e espaço. Um processo repleto de incertezas, de modos de se constituir que não podem ser previstos a priori na sua forma e natureza (Jesus, 2008, pp. 154-155).

Em seus relatos, os grupos falavam sobre como o acompanhamento os instigou a produzir, sistematizar e escrever. Essa foi uma experiência inovadora para eles. Suas aproximações potencializavam a implementação de ações compartilhadas comuns e também de apoio interpares.

Simultaneamente, observamos uma busca pela leitura dos textos disponibilizados pelos professores formadores ao longo do curso. No momento de produção, parecia que toda aquela bibliografia ganhava um novo sentido. Nesse movimento, instituiu-se um processo de coformação entre os que estão no cotidiano dos sistemas públicos de ensino e os pesquisadores da universidade, em uma implicação entre formar-se e mediar formações, reconhecendo o processo como um movimento longo e complexo de ação educativa, ou, como argumenta Pantaleão (2009), um processo de "formar-formando-se".

\section{A Produção Final dos Planos de Ação e as Mediações para sua Materialização}

A partir do processo de construção coletiva e colaborativa entre os profissionais-gestores, em novembro de 2011 os planos de trabalho e projetos de intervenção foram apresentados. Assim, todos ficaram conhecendo e tiveram a oportunidade de analisar cada um dos trabalhos, de um total de 45 .

A seguir destacamos algumas das discussões levantadas como elementos constitutivos dos planos de ação:

- Parceria entre SREs e Municípios: gerou-se grande interesse em criar projetos que efetivassem parcerias entre as instâncias estaduais e municipais (desde trocas de experiências ao partilhamento de recursos de pessoas e financeiros para ações conjuntas).

- Formação continuada: aspecto tido como primordial, tendo em vista que o início de todo o processo de conscientização e mobilização do movimento de inclusão passa pela formação do professor, tanto aquele do ensino comum quanto aquele especializado. Assim, muitos dos projetos elaborados contemplaram formações mais dinâmicas e direcionadas aos 
educadores de escolas das redes municipais e estadual.

- Criação e/ou potencialização do Setor de Educação Especial: uma vez que vários municípios ainda não possuíam esse Setor, houve uma ênfase em movimentos de mobilização em prol da estruturação desse espaço, a fim de que a Educação Especial fosse contemplada como espaço político e de ação. Isso também ocasionou a preocupação com a potencialização dos espaços que apresentam pouca expressividade. Além disso, os municípios que já possuem essa organização começaram a apoiar os municípios vizinhos que agora iniciavam esse processo.

- Parcerias com outras Secretarias, Universidade e outras instituições: seguindo o exemplo enriquecedor da parceria UFES e SEDU na experiência deste Curso de Formação, os participantes propuseram a continuação e ampliação, a fim de que todos sejam envolvidos e se sintam corresponsáveis pelo movimento de inclusão, em nível local e regional.

- Conhecer e fazer cumprir a Lei: o conhecimento legal entendido como mobilizador de intenções e ações. O setor de Educação Especial tem o compromisso de reivindicar os direitos legais de todos os alunos público-alvo, tendo em vista a garantia de seus direitos constitucionais.

- Criação de comitês e fóruns locais de Educação Especial: esta iniciativa visou a envolver a sociedade, em suas várias vertentes, para discutir e dinamizar o processo, articulando pais, gestores, professores e outros profissionais na responsabilidade de agir e apoiar ações que integrem o processo iniciado.

Do vivido fica claro que continuamos observando o Estado do Espírito Santo em suas semelhanças e diferenças. Há muitíssimo a ser realizado, contudo, conforme estudo realizado anteriormente (Jesus et al., 2009) “[...] se queríamos movimento, o ES está em movimento".

Dentro da proposição do curso, uma visita de acompanhamento a todos os subgrupos regionalmente organizados foi realizada entre os meses de abril e maio de 2012. A análise mais detalhada do conjunto dos projetos propostos em 2011 e os movimentos dos seis meses que se seguiram foram discutidos com os grupos.

Dentre as ações que ganharam mais destaque ou foram as possíveis de buscar implementar, destacam-se:

- criação ou reorganização do Setor de Educação Especial no contexto das Secretarias Municipais ou Superintendências Estaduais de Educação;

- aproximação das ações do Setor de Gestão de Pessoas para constituir ou ampliar o quadro de professores especializados tendo em vista desenvolver ações colaborativas com os demais profissionais da escola.

- Propostas de formação continuada para os professores como dispositivo de fortalecimento dos movimentos disparados pelo setor da Educação Especial em prol da implementação da política de inclusão escolar nos municípios;

- Promoção de articulações intersetoriais em nivel interno e externo às Secretarias Municipais de Educação $e$ às Superintendências Regionais de Educação, bem como articulações intersecretarias e interinstitucionais para fortalecer o processo de inclusão de alunos com deficiências, transtornos globais do desenvolvimento e altas habilidades/superdotação;

- preocupação dos gestores com o efetivo funcionamento das Salas de Recursos Multifuncionais para a oferta do atendimento educacional especializado;

- assunção de uma postura de mediadores de ações para fortalecimento dos pressupostos da inclusão escolar.

- acompanbamento ao Censo Escolar, tendo em vista um banco de dados sobre a efetivação de 
matrícula de alunos apoiados pela Educação Especial, visando a garantir serviços, profissionais, financiamento e participação nas políticas públicas em âmbito nacional;

- investimento na formação e articulação de ações com os pais ou responsáveis pelos alunos com indicativos à Educação Especial.

As ações são plurais. Na tentativa de materializar as propostas muitas negociações se estabeleceram no contexto das políticas locais. Em muitos municípios e superintendências, ações se tornaram realidade conforme o pensado. Em alguns, os processos se viram diante de muitas tensões, mas houve avanços, e outros encontram grandes impossibilidades de ordem material, técnica, política e humana.

Outros encaminhamentos que não estavam previstos nos projetos e planos de trabalho passaram a compor as agendas dos gestores. Muitas articulações foram desenvolvidas, porque o próprio cotidiano produzia essas demandas. Esse cenário evidenciava que a inclusão dos alunos com deficiência, transtornos globais do desenvolvimento e altas habilidades/superdotação não estava parada no Estado do Espírito Santo.

\section{Considerações Finais}

O que se discutiu sobre a formação de gestores públicos de Educação Especial nos permitiu constituir reflexões que aqui destacamos, principalmente em relação à importância do investimento na formação dos profissionais que assumem a gestão da Educação Especial nos cotidianos das Secretarias de Educação. São profissionais que demandam produzir conhecimentos sobre os pressupostos da inclusão escolar, gestão pública, trabalhos em redes intersetoriais, captação e aplicação de recursos financeiros e humanos, reorganização dos espaços escolares e formação de professores, dentre outras tantas atribuições. Precisam ainda articular políticas para que alunos com deficiência, transtornos globais do desenvolvimento e altas habilidades/superdotação tenham acesso à escolarização das escolas comuns e, quando necessário, que lhes seja garantido o atendimento educacional especializado na escola.

Considerando tais responsabilidades, argumentamos por outra perspectiva de gestão. Não uma gestão técnica, mas uma proposta que busca estabelecer uma orientação transformadora, a partir da dinamização de redes de relações que ocorrem, dialeticamente, no seu contexto interno e externo.

As reflexões sobre os movimentos disparados pelos protagonistas das políticas de Educação Especial, pela via das narrativas apresentadas pelos cursistas, mostraram-nos possibilidades de fazer visíveis ações que puderam ser articuladas a partir dos espaços locais e que, diante de situações conflituosas, não foram paralisantes dos fazeres daqueles envolvidos no estudo. Buscamos mostrar alguns modos de criar possibilidades:

- As reflexões realizadas nos encontros nos dizem da importância de oportunizar espaços e tempos para que gestores, responsáveis por implementar as políticas de Educação Especial, possam, no encontro com seus pares, refletir, partilhar seus fazeres e problematizar seus saberes a respeito das suas atribuições como gestores de políticas públicas de educação.

- O trabalho colaborativo surge como potencializador das ações em prol da inclusão escolar, envolvendo não somente os gestores e seus pares, no âmbito das Secretarias Municipais ou Superintendências Regionais De Educação, mas também profissionais que atuam "no chão da escola" e familiares dos alunos com deficiência, transtornos globais do desenvolvimento e altas habilidades/superdotação. 
- Os gestores parecem assumir uma responsabilização no que tange à garantia de uma educação de qualidade para os alunos com deficiência, transtornos globais do desenvolvimento e altas habilidades/superdotação.

- Nossas primeiras impressões apontam que as principais dificuldades dos cursistas para a articulação e operacionalização de suas propostas de trabalho estão relacionadas com o processo de burocratização e as desarticulações intergrupais e intragrupais. Evidencia-se a existência de entraves de cunho político-administrativo que dificultam a atuação dos gestores e a implementação dos planos de trabalho/ação, cujos objetivos giram em torno da garantia de acesso, e permanência, de todos os alunos a um ensino de qualidade. Há, no entanto, uma postura positiva assumida pelos gestores que, diante de tais desafios, têm se apresentado como sujeitos ativos.

- Há movimentos em todas as redes. Mesmo naquelas que demonstraram maiores dificuldades em colocar seus planos e projetos de trabalho em ação, há evidências de que novas negociações serão feitas. Podemos contemplar gestores inquietos e preocupados com os rumos da Educação Especial em seus contextos de atuação.

Do ponto de vista analítico, o uso da pesquisa-ação-formação, como disparadora das discussões e análises dos envolvidos, mostrou-se muito potente para o processo de constituir conhecimento sobre a realidade local. Conhecimento este que se forma considerando as análises críticas instituídas no coletivo, mas que contribuíram sobremaneira para os movimentos de cada um em seus espaços locais. Poderíamos evocar a noção de "pesquisador coletivo", assim como proposto por Barbier (2002). O autor sinaliza para a constituição de um grupo-sujeito formado pelos profissionais e pesquisadores, grupo este que funciona como mola propulsora das ações grupais nas quais se instituem as estratégias de intervenção (Givigi et al., 2012; Jesus, 2011). O estudo evidenciou que as rupturas advieram de um trabalho coletivo e de uma atitude propositiva e simultaneamente crítica.

Percebemos o impacto da articulação entre pesquisa e formação na constituição dos profissionais da educação. Como diz Freire (1992, p. 11), “[...] uma das tarefas do educador ou educadora progressista, através da análise política, séria e correta, é desvelar as possibilidades, não importando os obstáculos [...]". A relação entre pesquisa e formação aponta possibilidades para os gestores enfrentarem os desafios trazidos pelos pressupostos da inclusão escolar. Neste estudo os desafios presentes na gestão dos sistemas de ensino não foram acolhidos como ações paralisadoras, mas como oportunidades de formação e de instituição de novas políticas públicas inclusivas. Alarcão (2003) nos diz de uma atitude investigadora na profissão, que instiga a ações transformadoras, mesmo embrionárias, emergentes e instituintes de novas possibilidades.

Mudanças puderam ser captadas como flashes existenciais, como nos ensina Barbier (2002), quando dialoga sobre processos de mudança em pesquisa-ação. Buscamos contribuir para mudanças epistemológicas nas políticas locais e nas formas de ser/estar gestor público de Educação Especial.

Para provisoriamente finalizar, procuramos evidenciar experiências e conhecimentos que produziram formas de existência. Os profissionais gestores das ações voltadas para as pessoas público-alvo da Educação Especial puderam visibilizar seus saberes-fazeres e, a partir de ações coletivas de apoio, instituir, organizar e/ou reorganizar modos de gestão nos quais ganharam centralidade as políticas locais em ação, em articulação com as políticas educacionais gestadas em escalas regionais e nacionais. Simultaneamente, foi possível tensionar as políticas globais e visualizar como estas são vividas nos espaços locais. Buscamos nos afastar de propostas de formação, apontadas pelas atuais diretrizes que têm desencadeado a mercantilização da educação.

Nessa perspectiva, o profissional da educação precisa de um arcabouço teórico e prático que lhe possibilite conduzir suas ações, considerando as dimensões técnico-instrumentais, humanas e sócio-políticas (André, 2001). 
Conforme nos apontam Pimenta e Lima (2004) e André (2001), pesquisa e ensino devem ser articulados na formação inicial e continuada do profissional de educação, uma vez que, aproxima o professor da realidade educacional. Assim, os cursos de formação precisam organizar currículos que contribuam com a "desterritorialização" do conhecimento e dos saberes profissionais. Romper com a disciplinarização do conhecimento é um dos desafios das Instituições de Ensino Superior, para pensar a formação inicial e continuada docente no contexto atual.

Vaz (2008) corrobora esses argumentos ao fomentar a pesquisa como eixo de formação de profissionais da educação, na medida em que os envolvidos se tornem pesquisadores de suas próprias práticas. Movimento este que deve ser suscitado ao longo de todo o processo de formação inicial, como nos diria Nóvoa (1992, p. 28), “[...] a formação passa pela experimentação, pela inovação, pelo ensaio de novos modos de trabalho pedagógico. E por uma reflexão crítica sobre a sua utilização."

Queremos, ainda, evocar que uma ação conjunta da Universidade com grupos locais pode se constituir em uma rota sinalizadora de superações de conflitos, tensões e desafios que se colocam a uma ação emancipatória em torno da educação de todos.

\section{Referências}

Alarcão, I. (2003). Professores reflexivos em uma escola reflexiva. São Paulo, Brasil : Cortez.

Almeida, M. L. (2010). Uma análise da produção acadêmica sobre os usos da pesquisa-ação em processos de inclusão escolar: entre o agir comunicativo e o agir estratégico. Tese de Doutorado, Programa de PósGraduação em Educação, Universidade Federal do Espírito Santo, Vitória (ES), Brasil.

André, M. (Org.). (2001). O papel da pesquisa na formação e na prática dos professores. Campinas, Brasil: Papirus.

Araújo, G. C., \& Schwartz, C. M. (2009). O programa nacional escola de gestores da educação básica no Espírito Santo: reflexões sobre os desafios da formação continuada de diretores. In C. M. Schwartz, G. C. Araújo, \& P. S. Rodrigues (Eds.), Escola de gestores de educação básica: Democracia, formação e gestão escolar: reflexões e experiências do programa nacional Escola de Gestores da Educação Básica no Estado do Espírito Santo (pp. 09-20) Vitória, Brasil : GM Gráfica e Ed.

Barbier, R. (2002). A pesquisa-ação. (L. Didio, Trad.). Brasília: Liber Livro.

Caiado, K. R. M., Campos, J. A. P. P., \& Vilaronga, C. A. R. (2011). Estudo exploratório sobre o perfil, a formação e as condições de trabalho do professor. In K. R. M. Caiado, D. M. Jesus \& C. R. Baptista (Orgs.), Professores e educação Especial: formação em foco, 1, pp. 159-173. Porto Alegre: Mediação.

Caiado, K. R. M., \& Laplane, A. L. F. (2009). Programa Educação inclusiva: direito à diversidade uma análise a partir da visão de um município-pólo. Educação e Pesquisa, 35, pp. 303-315. http://dx.doi.org/10.1590/S1517-97022009000200006

Carr, W., \& Kemmis, S. (1988).Teoría crítica de la enseñanza: la investigación-acción en la formación del profesorado. J. A. Bravo, Trad. Barcelona, Spain: Martinez Roca.

Conselho Nacional de Educação (Brasil). (2001). Resolução CNE/CEB no. 2. Institui diretrizes nacionais para a educação especial da educação básica. Diário Oficial [da] República Federativa do Brasil, Brasília, 14 de set., seção 1E. Disponível em: http://portal.mec.gov.br/seesp/arquivos/pdf/diretrizes.pdf.

Conselho Nacional de Educação - CNE/CP. Brasil. (2006). Resolução 01/2006. Institui as Diretrizes Curriculares Nacionais para o curso de Pedagogia. Diário Oficial [da] República Federativa do Brasil, Brasília, de 15 de maio de 2006. Disponível em: http://portal.mec.gov.br/cne/arquivos/pdf/rcp01_06.pdf 
Espírito Santo (Estado). Secretaria de Educação. (2011). Diretriz̧es da educação especial na educação básica e profissional para a rede estadual de ensino. Vitória, Brasil: Sedu.

Figueiredo, R. V. (2010). Incluir não é inserir, mas interagir e contribuir. Inclusão, 4, 32-38.

Freire, P. (1992). Pedagogia da esperança: Um encontro com a pedagogia do oprimido. Rio de Janeiro, Brasil : Paz e Terra.

Garcia, R. M. C. (2011). Política nacional de educação especial nos anos 2000: A formação de professores e a hegemonia do modelo especializado. In K. R. M. Caiado, D. M. Jesus \& C. R. Baptista (Orgs.), Professores e educaşão Especial: Formação em foco, 2, pp.65-78. Porto Alegre, Brasil: Mediação.

Gatti, B. A. (2005). Grupo focal na pesquisa em ciências sociais e humanas. Brasília, Brasil: Líber Livro Ed.

Gatti, B. A. (2008). Análise das políticas públicas para formação continuada no Brasil, na última década. Revista Brasileira de Educação, 13(37), 57-71. Disponível em: http://www.scielo.br/scielo.php?script=sci_arttext\&pid=S141324782008000100006\&lng=pt\&nrm=iso

Givigi, R. C. N., Alves, F. L., Alcantara, J. N., \& Santos, K. N. (2012). A comunicação alternativa e os efeitos do trabalho em redes na constituição da linguagem nas práticas educativas inclusivas. Educaşão Unisinos, 1, 48-57.

Gonçalves, A. F. S. (2008). As políticas públicas e a formação continuada de professores na implementação da inclusão escolar no município de Cariacica. Tese de Doutorado, Programa de Pós-Graduação em Educação, Universidade Federal do Espírito Santo, Vitória (ES), Brasil.

Jesus, D. M. (2008). O que nos impulsiona a pensar a pesquisa-ação colaborativo-crítica como possibilidade de instituição de práticas educacionais mais inclusivas? In C. R. Baptista, K. R. M. Caiado, \& D. M. Jesus (Org.), Educação especial: Diálogo e pluralidade (pp. 139-160). Porto Alegre, Brasil: Mediação.

Jesus, D. M. (2009). Políticas de Educação, Inclusão Escolar e Diversidade pelo olhar daqueles que as praticam: por diferentes trilhas. (Relatório técnico de pesquisa). Vitória (ES): Universidade Federal do Espírito Santo, Programa de Pós-Graduação em Educação, Brasil.

Jesus, D. M. (2011). Política de Inclusão Escolar: cartografando o Espírito Santo. In S. L. Victor, R. Drago, \& J. F. Chicon (Eds.), Educação especial e inclusiva: conbecimentos, experiências e formação (pp. 65-90). Araraquara, Brasil: Junqueira \& Marin Ed.

Jesus, D. M. (2012). (Org.). Gestão da educação educação especial: Pesquisa, política e formação. Curitiba, Brasil: Apris.

Jesus, D. M., \& Alves, E. P. (2011). Serviços educacionais especializados: desafios à formação inicial e continuada. In K. R. M. Caiado, D. M. Jesus, \& C. R. Baptista (Orgs.), Professores e educação Especial: Formação em foco (Vol. 1, pp.17-21). Porto Alegre, Brasil : Mediação.

Lapassade, G. (2005). As microssociologias. Lucie Didio, Trad. Brasília, Distrito Federal, Brasil: Líber Livros.

Laplane, A. L. F., \& Caiado, K. R. M. (2008). Educação inclusiva: Opapel das parcerias na implementação das políticas públicas [Resumo]. Anais do Simpósio Internacional "O Estado e as Politicas Educacionais no tempo presente", e Simpósio Internacional "O Estado e as Politicas Educacionais no tempo presente”, Uberlândia, Brasil, 4(1), 70-70. Uberlândia: Universidade Federal de Uberlândia.

Lima, L. C. (2008). A escola como organização educativa: uma abordagem sociológica. 3. ed. São Paulo, Brasil : Cortez.

Magalhães, R. C. B. P., \& Cardoso, A. P. L. B. (2011). Educação Especial e educação inclusiva: conceitos e políticas educacionais. In R. C. B. P. Magalhães (Org.), Educação inclusiva: Escolarização, política e formação docente (pp. 13-34). Distrito Federal, Brasília: Liber Livro. 
Meirieu, P. (2005). O cotidiano da escola e da sala de aula: o fazer e o compreender. Porto Alegre, Brasil: Artmed.

Ministério da Educação. Brasil. (2005). Programa Educação Inclusiva: direito à diversidade. Brasília, Distrito Federal. Disponível em: http://portal.mec.gov.br/seesp/arquivos/pdf/orientador1.pdf.

Ministério da Educação. Brasil. (2008). Política pública de educação especial na perspectiva da educação inclusiva. Brasília, Distrito Federal. Disponível em: http://portal.mec.gov.br/arquivos/pdf/politicaeducespecial.pdf

Nóvoa, A. (1992). Formação de professor e profissão docente. In A. Nóvoa. (Coord.), Os professores e a sua formação. Lisboa, Portugal: Porto.

Pantaleão, E. (2009). Formar formando-se nos processos de gestão e inclusão escolar. Tese de doutorado em Educação, Programa de Pós-Graduação em Educação, Universidade Federal do Espírito Santo, Vitória (ES), Brasil.

Parrila, A. (2011). O desenvolvimento local um argumento para uma educação mais inclusiva. In D. Rodrigues (Org.), Educação Inclusiva: dos conceitos às práticas de formação (pp.17-28). Lisboa, Portugal: Horizontes Pedagógicos.

Passerino, L. M. (2011). Uma experiência em formação de professores na modalidade EAD. In K. R. M. Caiado, D. M. Jesus \& C. R. Baptista (Orgs.), Professores e educação Especial: Formação em foco (Vol. 1, pp.75-90). Porto Alegre, Brasil: Mediação.

Pimenta, S. G., \& Lima, M. S. L. (2004). Estágio e docência. São Paulo, Brasil : Cortez.

Rodrigues, D.\& Lima-Rodrigues, L. (2011,). Formação de Professores e Inclusão: como se reformam os reformadores? Educar em Revista, 41, 41-60.

Santos, B. S. (2006). Para uma sociologia das ausências e uma sociologia das emergências. In B. S. Santos (Org.), Conbecimento prudente para uma vida decente: Um discurso sobre as ciências revisitado (pp.777-813). São Paulo, Brasil : Cortez.

Santos, W. (2009). Programa escola de gestores: um olhar sobre as práticas curriculares e avaliativas. In C. M. Schwartz, G. C. Araújo, \& P. S. Rodrigues (Eds.), Escola de gestores de educação básica: Democracia, formação e gestão escolar: reflexões e experiências do programa nacional escola de gestores da educação básica no Estado do Espírito Santo. Vitória, Brasil: GM Gráfica e Ed.

Silva, T. T. da. (2005). Documentos de identidade: Uma introdução às teorias do currículo. Belo Horizonte, Brasil: Autêntica.

Tezzari, M. L. \& Baptista, C. R. (2011). A medicina como origem e a pedagogia como meta da ação docente na educação especial. In K. R. M. Caiado, D. M. Jesus \& C. R. Baptista (Orgs.), Professores e educação Especial: formação em foco (Vol. 1, pp.19-34). Porto Alegre, Brasil Mediação.

Vaz, A. F. (2008). Sobre a relação ensino-pesquisa na formação inicial em educação física. Motrivivencia, 30, 76-90.

Vieira, A. B., Cuevas, M. R. C., \& Ramos, I. O. (2012). Os movimentos disparados pelo curso de gestores públicos em educação especial: O que dizem os planos de trabalho elaborados pelos sujeitos em formação? In D. M. Jesus (Org.), Gestão da educação especial: pesquisa, política e formação (pp.191-208). Curitiba, Brasil: Appris \& Vitória (ES) 


\section{Sobre os Autores}

\section{Denise Meyrelles de Jesus}

Professora do Departamento de Educação, Política e Sociedade e do Programa de PósGraduação em Educação/Centro de Educação/Universidade Federal do Espírito Santo jesusdenise@hotmail.com

A autora é pesquisadora na área de Educação, com ênfase em Política de Educação

Especial, Formação Continuada de Profissionais da Educação na perspectiva da inclusão escolar e Práticas Educacionais Inclusivas. Atua como professora da graduação e do Programa de PósGraduação em Educação da Universidade Federal do Espírito Santo. É membro Grupo de Pesquisa (CNPq) Educação Especial: formação de profissionais, práticas pedagógicas e políticas públicas. Atualmente, desenvolve os seguintes projetos de pesquisas: a) Observatório Nacional de Educação Especial: avaliando a política de salas de recursos multifuncionais; b) Observatório Estadual de Educação Especial: o caso do Espirito Santo e c) Políticas de acesso e de permanência de pessoas com deficiência no ensino comum: um estudo comparado de sistemas educativos brasileiros e mexicanos. Organizou em parceria com outros pesquisadores, entre outros, os livros "Prática pedagógica na educação especial: multiplicidade do atendimento educacional especializado"; "Políticas, Práticas Pedagógicas e Formação: Dispositivos para a escolarização de alunos (as) com deficiência" e "Professores e Educação Especial - formação em foco". Tem vários capítulos de livros e artigos publicados em revistas científicas nacionais e internacionais.

\section{Edson Pantaleão}

Professor do Departamento de Educação, Política e Sociedade e do Programa de PósGraduação em Educação/Centro de Educação/Universidade Federal do Espírito Santo edpantaleao@hotmail.com

O autor é pesquisador na área de Educação, com ênfase em Política e Gestão da Educação Especial, Gestão Escolar e Formação Continuada de Profissionais da Educação na perspectiva da inclusão escolar. Atua como professor da graduação e do Programa de Pós-Graduação em Educação da Universidade Federal do Espírito Santo. É membro do grupo de pesquisa (CNPq) Educação Especial: formação de profissionais, práticas pedagógicas e políticas e inclusão escolar. Atualmente desenvolve os seguintes projetos de pesquisa: a) Política e gestão da educação especial no Estado do Espírito Santo: processos de instituição e organização dos setores de educação especial nos Municípios capixabas; b) Políticas de acesso e de permanência de pessoas com deficiência no ensino comum: um estudo comparado de sistemas educativos brasileiros e mexicanos. Este último em colaboração com o professor Dr. Reginaldo Célio Sobrinho. Organizou em parceria com outros pesquisadores, entre outros, os livros "Educação especial no cenário educacional brasileiro" e "Educação especial: indícios, registros e práticas de inclusão". Tem vários artigos publicados em livros e revistas científicas.

\section{Mariangela Lima de Almeida}

Professora do Departamento de Educação, Política e Sociedade / Centro de Educação/Universidade Federal do Espírito Santo mlalmeida.ufes@gmail.com

A autora é pesquisadora na área de Educação, com ênfase em Formação Continuada e Prática Docente na perspectiva da Inclusão Escolar; Formação e atuação de gestores públicos de Educação Especial e Produção do conhecimento científico em Educação Especial. Atua na docência, pesquisa 
e extensão na Universidade Federal do Espírito Santo. É membro Grupo de Pesquisa (CNPq) Educação Especial: formação de profissionais, práticas pedagógicas e políticas públicas. Atualmente, coordena o projeto de pesquisa Processos de formação continuada de profissionais desencadeados pela gestão de educação especial: a região sul do Espirito Santo; os projetos de extensão Formação continuada de profissionais no estado do espirito santo: processos constituidos pela gestão de educação especial e Formação continuada de conselheiros municipais de educação - Pró-Conselho e, também, coordena o projeto de inovação tecnológica $A$ constituição de um fórum de gestores de Educação Especial a partir de um website. É autora do livro "Prática pedagógica inclusiva: a diferença como possibilidade”, em colaboração com Ines de Oliveira Ramos. Organizou em parceria com outros pesquisadores o livro "Diálogos sobre práticas pedagógicas inclusivas". Tem vários capítulos de livros e artigos publicados em revistas científicas.

\section{Sobre as Editoras Convidadas}

\section{Márcia Denise Pletsch}

Professora do Programa de Pós-Graduação em Educação, Contextos Contemporâneos e Demandas Populares (PPGEduc) na linha de pesquisa Estudos Contemporâneos e Práticas Educativas e do Departamento Educação e Sociedade da Universidade Federal Rural do Rio de janeiro. marciadenisepletsch@gmail.com

A autora é pesquisadora na área de Educação Especial, atuando na formação de professores e de novos pesquisadores. É líder do Grupo de Pesquisa (CNPq) Observatório de Educação Especial e inclusão escolar: práticas curriculares e processos de ensino e aprendizagem e, por meio de convênio interinstitucional entre a UFRRJ e a Universidade do Estado do Rio de Janeiro (UERJ), também é líder do grupo de pesquisa Inclusão e aprendizagem de alunos com necessidades educacionais especiais: práticas pedagógicas, cultura escolar e aspectos psicossociais. Atualmente, coordena o Programa Observatório da Educação da CAPES com projeto de pesquisa em rede na área de deficiência intelectual envolvendo a Universidade Estadual de Santa Catarina (UDESC), Universidade do Vale do Itajaí (UNIVALI); e coordena também pesquisas financiadas pela FAPERJ na área de deficiência múltipla. É autora do livro "Repensando a inclusão escolar: diretrizes políticas, práticas curriculares e deficiência intelectual" e, em colaboração com Rosana Glat, do livro "Inclusão escolar de alunos com necessidades especiais". Organizou em parceria com outros pesquisadores, entre outros, os livros "Estratégias educacionais diferenciadas para alunos com necessidades especiais" e "Educação Especial e inclusão escolar: reflexões sobre o fazer pedagógico”. Tem mais de vinte artigos publicados em revistas científicas nacionais e internacionais.

\section{Geovana Mendonça Lunardi Mendes}

Professora do Programa de Pós-Graduação em Educação e do Departamento de Pedagogia da Universidade do Estado de Santa Catarina (PGE-UDESC) geolunardi@gmail.com

A autora é pesquisadora na área de Educação Especial e dos Estudos Curriculares. Realizou PósDoutorado na Argentina e nos Estados Unidos da América, na área de Currículo e Novas Tecnologias, na Universidad de San Andres em Buenos Aires e em Ashland University, em Ohio. É pesquisadora coordenadora de diferentes projetos de investigação e participa como pesquisadora convidada em projetos de pesquisa nacionais e internacionais. Suas pesquisas e produções têm sido voltadas para área de Currículo e práticas escolares, em especial, as questões relativas as mudanças, novas tecnologias e inovações curriculares no espaço escolar, e também as práticas curriculares voltadas a inclusão de sujeitos com deficiência. Atualmente é a Coordenadora Nacional do Consórcio "Educação e Diversidade" do programa CAPES. FIPSE de Cooperação Internacional, 
envolvendo a Universidade Federal Rural do Rio de Janeiro, no Brasil e Georgetown College, Ashland University e Brighman Young University nos Estados Unidos e também do Projeto de Pesquisa: Aulas conectadas: mudanças curriculares e aprendizagem colaborativa nas escolas do PROUCA em Santa Catarina, com financiamento do CNPq e do Projeto Observatório de Práticas Escolares com financiamento da FAPESC. É coordenadora do Programa de Pós-graduação em Educação, Mestrado e Doutorado, da FAED, UDESC. Coordena o Observatório da Educação: Tablets, Computadores e Laptops, aprovado no Edital OBEDUC/CAPES. Entre suas atuais produções podem ser destacadas o livro intitulado "Objetos Pedagógicos: uma experiência inclusive em oficinas de Artes", em parceria com mais duas autoras e a organização do Livro "Deficiência e Escolarização: novas perspectivas de analise", hoje na segunda edição. É autora de inúmeros capítulos e artigos publicados em periódicos.

\title{
DOSSIÊ \\ Educação Especial: Diferenças, Currículo e Processos de Ensino e Aprendizagem II arquivos analíticos de políticas educativas
}

Volume 23 Número 29
16 de março de 2015
ISSN 1068-2341

\begin{abstract}
(c)
SORERIGHIS RESEREED O Copyright e retido pelo/a o autor/a (ou primeiro co-autor) que outorga o direito da primeira publicação à revista Arquivos Analíticos de Políticas Educativas. Más informação da licença de Creative Commons encontram-se em http://creativecommons.org/licenses/by-nc-nd/2.5. Qualquer outro uso deve ser aprovado em conjunto pelo/s autor/es e por AAPE/EPAA. AAPE/EPAA é publicada por Mary Lou Fulton Institute Teachers College da Arizona State University. Os textos publicados em AAPE são indexados por CIRC (Clasificación Integrada de Revistas Científicas, Espanha) DIALNET (Espanha),Directory of Open Access Journals, Education Full Text (H.W. Wilson), EBSCO Education Research Complete, , ERIC, , QUALIS A2 (Brasil), SCImago Journal Rank; SCOPUS, SOCOLAR (China). Contribua com comentários e sugestões a http://epaa.info/wordpress/ ou para Gustavo E. Fischman fischman@,asu.edu.
\end{abstract}

Curta a nossa comunidade EPAA's Facebook https://www.facebook.com/EPAAAAPE e Twitter feed @epaa_aape. 


\section{arquivos analíticos de políticas educativas conselho editorial}

Editor: Gustavo E. Fischman (Arizona State University)

Editores Associados: Rosa Maria Bueno Fisher e Luis A. Gandin

(Universidade Federal do Rio Grande do Sul)

Dalila Andrade de Oliveira Universidade Federal de Minas Gerais, Brasil

Paulo Carrano Universidade Federal Fluminense, Brasil

Alicia Maria Catalano de Bonamino Pontificia Universidade Católica-Rio, Brasil

Fabiana de Amorim Marcello Universidade Luterana do Brasil, Canoas, Brasil

Alexandre Fernandez Vaz Universidade Federal de Santa Catarina, Brasil

Gaudêncio Frigotto Universidade do Estado do Rio de Janeiro, Brasil

Alfredo M Gomes Universidade Federal de Pernambuco, Brasil

Petronilha Beatriz Gonçalves e Silva Universidade Federal de São Carlos, Brasil

Nadja Herman Pontificia Universidade Católica -Rio Grande do Sul, Brasil

José Machado Pais Instituto de Ciências Sociais da Universidade de Lisboa, Portugal

Wenceslao Machado de Oliveira Jr. Universidade Estadual de Campinas, Brasil
Jefferson Mainardes Universidade Estadual de Ponta Grossa, Brasil

Luciano Mendes de Faria Filho Universidade Federal de Minas Gerais, Brasil

Lia Raquel Moreira Oliveira Universidade do Minho, Portugal

Belmira Oliveira Bueno Universidade de São Paulo, Brasil

António Teodoro Universidade Lusófona, Portugal

Pia L. Wong California State University Sacramento, U.S.A

Sandra Regina Sales Universidade Federal Rural do Rio de Janeiro, Brasil

Elba Siqueira Sá Barreto Fundação Carlos Chagas, Brasil

Manuela Terrasêca Universidade do Porto, Portugal

Robert Verhine Universidade Federal da Bahia, Brasil

Antônio A. S. Zuin Universidade Federal de São Carlos, Brasil 


\section{education policy analysis archives editorial board}

Editor Gustavo E. Fischman (Arizona State University)

Associate Editors: Audrey Amrein-Beardsley (Arizona State University), Rick Mintrop, (University of California, Jeanne M. Powers (Arizona State University)

Jessica Allen University of Colorado, Boulder

Gary Anderson New York University

Michael W. Apple University of Wisconsin, Madison

Angela Arzubiaga Arizona State University

David C. Berliner Arizona State University

Robert Bickel Marshall University

Henry Braun Boston College

Eric Camburn University of Wisconsin, Madison

Wendy C. Chi* University of Colorado, Boulder

Casey Cobb University of Connecticut

Arnold Danzig Arizona State University

Antonia Darder University of Illinois, UrbanaChampaign

Linda Darling-Hammond Stanford University

Chad d'Entremont Strategies for Children

John Diamond Harvard University

Tara Donahue Learning Point Associates

Sherman Dorn University of South Florida

Christopher Joseph Frey Bowling Green State University

Melissa Lynn Freeman* Adams State College

Amy Garrett Dikkers University of Minnesota

Gene V Glass Arizona State University

Ronald Glass University of California, Santa Cruz

Harvey Goldstein Bristol University

Jacob P. K. Gross Indiana University

Eric M. Haas WestEd

Kimberly Joy Howard* University of Southern California

Aimee Howley Ohio University

Craig Howley Ohio University

Steve Klees University of Maryland

Jaekyung Lee SUNY Buffalo
Christopher Lubienski University of Illinois, UrbanaChampaign

Sarah Lubienski University of Illinois, UrbanaChampaign

Samuel R. Lucas University of California, Berkeley

Maria Martinez-Coslo University of Texas, Arlington

William Mathis University of Colorado, Boulder

Tristan McCowan Institute of Education, London

Heinrich Mintrop University of California, Berkeley

Michele S. Moses University of Colorado, Boulder

Julianne Moss University of Melbourne

Sharon Nichols University of Texas, San Antonio

Noga O'Connor University of Iowa

João Paraskveva University of Massachusetts, Dartmouth

Laurence Parker University of Illinois, UrbanaChampaign

Susan L. Robertson Bristol University

John Rogers University of California, Los Angeles

A. G. Rud Purdue University

Felicia C. Sanders The Pennsylvania State University

Janelle Scott University of California, Berkeley

Kimberly Scott Arizona State University

Dorothy Shipps Baruch College/CUNY

Maria Teresa Tatto Michigan State University

Larisa Warhol University of Connecticut

Cally Waite Social Science Research Council

John Weathers University of Colorado, Colorado Springs

Kevin Welner University of Colorado, Boulder

Ed Wiley University of Colorado, Boulder

Terrence G. Wiley Arizona State University

John Willinsky Stanford University

Kyo Yamashiro University of California, Los Angeles

* Members of the New Scholars Board 


\section{archivos analíticos de políticas educativas consejo editorial}

Editor: Gustavo E. Fischman (Arizona State University)

Editores. Asociados Alejandro Canales (UNAM) y Jesús Romero Morante (Universidad de Cantabria)

Armando Alcántara Santuario Instituto de Investigaciones sobre la Universidad y la Educación, UNAM México

Claudio Almonacid Universidad Metropolitana de Ciencias de la Educación, Chile

Pilar Arnaiz Sánchez Universidad de Murcia, España

Xavier Besalú Costa Universitat de Girona, España

Jose Joaquin Brunner Universidad Diego Portales, Chile

Damián Canales Sánchez Instituto Nacional para la Evaluación de la Educación, México

María Caridad García Universidad Católica del Norte, Chile

Raimundo Cuesta Fernández IES Fray Luis de León, España

Marco Antonio Delgado Fuentes Universidad Iberoamericana, México

Inés Dussel FLACSO, Argentina

Rafael Feito Alonso Universidad Complutense de Madrid, España

Pedro Flores Crespo Universidad Iberoamericana, México

Verónica García Martínez Universidad Juárez Autónoma de Tabasco, México

Francisco F. García Pérez Universidad de Sevilla, España

Edna Luna Serrano Universidad Autónoma de Baja California, México

Alma Maldonado Departamento de Investigaciones Educativas, Centro de Investigación y de Estudios Avanzados, México

Alejandro Márquez Jiménez Instituto de Investigaciones sobre la Universidad y la Educación, UNAM México

José Felipe Martínez Fernández University of California Los Angeles, USA
Fanni Muñoz Pontificia Universidad Católica de Perú

Imanol Ordorika Instituto de Investigaciones Economicas - UNAM, México

Maria Cristina Parra Sandoval Universidad de Zulia, Venezuela

Miguel A. Pereyra Universidad de Granada, España

Monica Pini Universidad Nacional de San Martín, Argentina

Paula Razquin UNESCO, Francia

Ignacio Rivas Flores Universidad de Málaga, España

Daniel Schugurensky Arizona State University

Orlando Pulido Chaves Universidad Pedagógica Nacional, Colombia

José Gregorio Rodríguez Universidad Nacional de Colombia

Miriam Rodríguez Vargas Universidad Autónoma de Tamaulipas, México

Mario Rueda Beltrán Instituto de Investigaciones sobre la Universidad y la Educación, UNAM México

José Luis San Fabián Maroto Universidad de Oviedo, España

Yengny Marisol Silva Laya Universidad Iberoamericana, México

Aida Terrón Bañuelos Universidad de Oviedo, España

Jurjo Torres Santomé Universidad de la Coruña, España

Antoni Verger Planells University of Amsterdam, Holanda

Mario Yapu Universidad Para la Investigación Estratégica, Bolivia 